\title{
Nanostructured Systems Obtention Using LbL Self-Assembly or the Cysteine-Assisted Adsorption Method and Their Application as a Water Splitting Single Catalyst
}

\author{
Rhauane A. Galvão, ${ }^{\oplus \#, a, b}$ Paloma B. Barreto, ${ }^{a, c}$ Thiago A. S. Soares, ${ }^{\circledR a, c}$ Letícia B. V. Sales, ${ }^{a, c}$

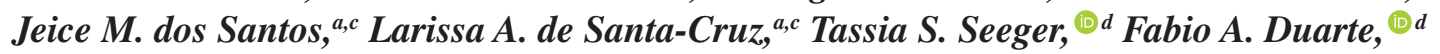 \\ Germana M. M. Silva ${ }^{a}$ and Giovanna Machado ${ }^{\circledR *, a}$ \\ ${ }^{a}$ Laboratório de Nanomateriais, Centro de Tecnologias Estratégicas do Nordeste (CETENE), \\ 50740-545 Recife-PE, Brazil \\ ${ }^{b}$ Departamento de Engenharia Mecânica, Centro de Tecnologia e Geociências (CTG), \\ Universidade Federal de Pernambuco (UFPE), 50740-550 Recife-PE, Brazil \\ cPrograma de Pós-graduação em Ciência de Materiais (PGMtr), \\ Centro de Ciências Exatas e da Natureza (CCEN), Universidade Federal de Pernambuco (UFPE), \\ 50740-560 Recife-PE, Brazil \\ ${ }^{d}$ Departamento de Química, Universidade Federal de Santa Maria (UFSM), \\ 97105-900 Santa Maria-RS, Brazil
}

\begin{abstract}
The present work evaluated the effect on charge transfer in functionalized $\mathrm{TiO}_{2}$ nanostructured systems using different binders. We highlight the conditions required to form self-assembled systems by varying the number of layers, as well as by substituting them for an organic binder, cysteine. Additionally, we study the $\mathrm{pH}$ effect of the precursor solution $\left(\mathrm{HAuCl}_{4}\right)$ on gold nanoparticles (AuNPs) formation. The morphological characterization allowed us to determine the percentage of $\mathrm{Au}$ atoms on the surface of the synthesized nanoparticles. Inductively coupled plasma mass spectrometry (ICP-MS) analysis determined the amount of gold deposited on the $\mathrm{TiO}_{2}$ surface, which ranged from 4.56 to $253.00 \mathrm{ng} \mathrm{mm}^{-2}$ depending on the system used. Based on Fourier-transform infrared spectroscopy (FTIR) and Raman analysis, it was possible to propose a photolysis mechanism for AuNP formation in accordance with the change in the binders. The different systems were subjected to hydrogen photogeneration by a water splitting process, resulting in $2.02 \mu \mathrm{mol} \mathrm{cm}{ }^{-2}$ of hydrogen production for cysteine binder [Cys+ $\mathrm{HAuCl}_{4}-2.7$ ]. There proved to be an excellent synergy between the morphological aspects, crystallinity, and stability of this arrangement.
\end{abstract}

Keywords: solar energy, $\mathrm{TiO}_{2}$, photocatalysts, gold, binding agents

\section{Introduction}

Energy is required for most human activities and, because of this, worldwide energetic demand has grown in recent decades. The predominance of the use of fossil fuels, such as oil, coal and natural gas, overwhelm the investments in more sustainable energies sources. ${ }^{1}$ Due to the progressive exhaustion of these nonrenewable sources and their negative impact on the environment (e.g., water pollution, carbon dioxide $\left(\mathrm{CO}_{2}\right)$ and global warming gas

*e-mail: giovanna.machado@cetene.gov.br

\#Present address: Programa de Pós-graduação em Ciência de Materiais (PGMtr), Centro de Ciências Exatas e da Natureza (CCEN), Universidade Federal de Pernambuco (UFPE), 50740-560 Recife-PE, Brazil emissions), the search for new and renewable sources is receiving increasing attention from different governments and research institutions all over the world. ${ }^{2}$ Among them, solar energy has been outstanding as a result of being the most abundant source that might be able to supply the world demand..$^{3,4}$

Since the first study was undertaken by Fujishima and Honda in $1972,{ }^{5}$ hydrogen production through solar-assisted water splitting has gained great attention, and recent studies have shown that the photogenerated production of $\mathrm{H}_{2}$ is potentially competitive when compared with traditional methods based on nonrenewable sources. ${ }^{4}$ Photocatalytic hydrogen production consists of water splitting using a semiconductor as a catalyst for the reaction. The process 
occurs in three steps: (i) photon absorption with energy at least equal to their bandgap, exciting its electrons from the valence to conduction band, and generating an electron-hole pair $\left(\mathrm{e}^{-} / \mathrm{h}^{+}\right)$; $(i i)$ the $\mathrm{e}^{-} / \mathrm{h}^{+}$pair goes to the semiconductor surface and (iii) the photogenerated charges promote the reduction and oxidation, splitting water into hydrogen and oxygen $\left(\mathrm{O}_{2}\right){ }^{6}$ Titanium dioxide $\left(\mathrm{TiO}_{2}\right)$ has been widely used due to its nontoxicity, low cost, high chemical stability and durability. ${ }^{4,6-10}$ However, its activity is limited to ultraviolet (UV) radiation, which is just 5\% of the solar spectrum. To achieve better efficiency, the addition of a cocatalyst to the $\mathrm{TiO}_{2}$ surface increases the light-absorption capacity. ${ }^{11,12}$ Noble metal nanoparticles (NPs), such as gold, are well known cocatalysts ${ }^{13}$ due to their optical, electrical, magnetic and catalytic properties, as well as their visiblelight absorption enabled by the surface plasmon resonance (SPR) effect, which is generally between 520 to $560 \mathrm{~nm} . .^{14,15}$

One approach to increase nanoparticle adhesion on the nanotubes' (NTs) surface is through the use of organic short compounds with different functional groups that can be linked to the nanotubes and act as the nanoparticles' point of nucleation and growth. For example, since $\mathrm{pH}$ change can alternate the charge of its three functional groups, cysteine has been employed as a linker compound in some nanostructures, and it is able to interact with different compounds, because their groups can be in different states of protonation. ${ }^{16}$ Another way to functionalize a surface is through layer-by-layer (LbL) assembly, which is a promising method that produces nanostructured thin films with functionalized molecules over solid substrates with controlled thicknesses. ${ }^{17-20}$ This technique is based on the deposition of alternately charged molecules, commonly polyelectrolytes, i.e., polycations (positive) and polyanions (negative), ${ }^{21}$ which can act as nanoreactors for metallic and semiconductor adsorption upon simple adjustment of pH solutions. ${ }^{19,22-24}$ Poly(allylamine hydrochloride) (PAH) and poly(acrylic acid) (PAA) have been widely used as polyelectrolytes for gold nanoparticles adhesion. ${ }^{17,23,25}$

In this work, we investigate the functionalization of titanium dioxide nanotubes through different methods to more efficiently attract gold nanoparticles from precursor solution with different $\mathrm{pH}$ values (e.g., $\mathrm{HAuCl}_{4}$ with $\mathrm{pH}$ $1.8,2.3$, and 2.7), and we explore the application in solarassisted hydrogen generation.

\section{Experimental}

\section{$\mathrm{TiO}_{2}$ nanotubes synthesis}

The $\mathrm{TiO}_{2}$ nanotubes were produced with $98.6 \%$ of purity by an anodization process on commercial titanium
(Ti) foil that was previously cleaned with Extran 10\% and acetone coupled with sonication for $2 \mathrm{~min}$. The growth of nanotubes by anodization on Ti foil was obtained by means of a copper counter electrode in an electrolyte solution of ethylene glycol (ETG) with 10 wt.\% distilled $\mathrm{H}_{2} \mathrm{O}$ (water) and $0.25 \mathrm{wt} . \% \mathrm{NH}_{4} \mathrm{~F}$ (ammonium fluoride) under an applied potential of $30 \mathrm{~V}$ for $30 \mathrm{~min}$. Afterwards, the samples were washed in distilled water and sonicated in acetone for $30 \mathrm{~s}$ to remove excess of reactants.

\section{Solutions preparation}

Electrolytic solutions: poly(allylamine hydrochloride) (PAH, MW $=70.000 \mathrm{~g} \mathrm{~mol}^{-1}$, Figure 1A) and poly(acrylic acid) (PAA, $\mathrm{MW} \geq 200.000 \mathrm{~g} \mathrm{~mol}^{-1}$, Figure $1 \mathrm{~B}$ ) were used as the polycation and polyanion, respectively. All polyelectrolytes were used as received without further purification. PAH and PAA were prepared in $1 \times 10^{-2} \mathrm{~mol} \mathrm{~L}^{-1}$ solutions (based on the repeat-unit molecular weight). The $\mathrm{pH}$ of PAH and PAA solutions was adjusted for 7.5 and 3.5 , respectively, and the $\mathrm{pH}$ of the polyelectrolyte solutions was adjusted with a $0.1 \mathrm{~mol} \mathrm{~L}^{-1}$ solution of $\mathrm{HCl}$ or $0.1 \mathrm{~mol} \mathrm{~L}^{-1}$ solution of $\mathrm{NaOH}$, respectively. The as-prepared solutions were used for thin film deposition onto a nanotubular matrix of $\mathrm{TiO}_{2}$.

The L-cysteine (Figure 1C) solution $1 \times 10^{-2} \mathrm{~mol} \mathrm{~L}^{-1}$ was prepared with deionized water, and the $\mathrm{pH}$ was adjusted for 6.0.

The tetrachloroauric(III) acid $\left(\mathrm{HAuCl}_{4}\right) 5 \times 10^{-3} \mathrm{~mol} \mathrm{~L}^{-1}$ solution in deionized water was used as a precursor of the AuNPs. The assays were performed under three different pH values: 1.8, 2.3 and 2.7.
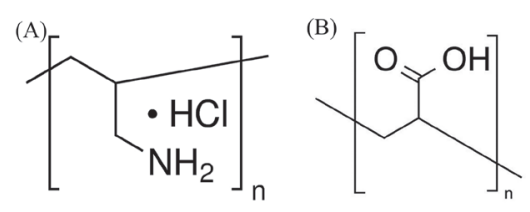<smiles>NC(CS)C(=O)O</smiles>

Figure 1. Structural formula of compounds (A) PAH, (B) PAA, and (C) cysteine.

\section{Functionalization methods}

The nanotubes were functionalized by two different methods: (i) using the electrolyte solution of PAH and PAA or (ii) prepared with cysteine as the previous description.

\section{Multilayer deposition by the LbL method}

Self-assembled thin films were prepared using a NanoStracto Sequence equipment. In this case, the NTs were immersed in the polycation aqueous solution (PAH) for $15 \mathrm{~min}$ before rinsing with deionized water once for 
2 min and twice for $1 \mathrm{~min}$. Next, the $\mathrm{TiO}_{2} \mathrm{NT}$ s containing the adsorbed polycation were dipped into the polyanion solution (PAA) for $15 \mathrm{~min}$, and the samples were rinsing again, as previously described. After these steps, there was a bilayer. After completing the total numbers of bilayers, we have the formula $\left[\mathrm{PAH}_{7.5} / \mathrm{PAA}_{3.5}\right]_{\mathrm{n}}$, where $\mathrm{n}=5 ; 5.5$ represents the total number of bilayers at the end of the process. Tests with $\mathrm{n}=$ 10; 10.5 were made, but its results in hydrogen generation were unsatisfactory in comparison to the samples with $n=$ $5 ; 5.5$, so they were not characterized further.

\section{Functionalization with cysteine}

In this method $\mathrm{TiO}_{2}$ nanotubes were immersed in a cysteine solution ( $\mathrm{pH}$ 6.0) for $16 \mathrm{~h}$. Then, the samples were washed with deionized water and left to dry.

\section{Nanotubes sensitized with AuNPs}

To test the influence of the binder, the functionalized nanotubular samples were sensitized with gold salt for further reduction. The samples were immersed in an $\mathrm{HAuCl}_{4}\left(5 \times 10^{-3} \mathrm{~mol} \mathrm{~L}^{-1}\right)$ solution with different $\mathrm{pH}$ values (i.e., 1.8, 2.3, 2.7) for $2 \mathrm{~h}$. Then, the samples were washed with deionized water and subjected to $24 \mathrm{~h}$ of UV radiation with a $365 \mathrm{~nm}$ frequency lamp (G5 Xelux - $6 \mathrm{~W}$ ) for $\mathrm{Au}^{3+}$ to $\mathrm{Au}^{0}$ reduction.

\section{Heat treatment}

Finally, the samples were heat treated at $400{ }^{\circ} \mathrm{C}$ for $3 \mathrm{~h}$ (heat at $10{ }^{\circ} \mathrm{C} \mathrm{min}^{-1}$ ) to obtain the anatase phase of $\mathrm{TiO}_{2}$ and the calcination of the organic compounds from the binders.

\section{Characterization}

To avoid misunderstandings, the samples with polyelectrolyte were named according to the following scheme: $\left[\mathrm{PAH}_{\mathrm{x}} / \mathrm{PAA}_{\mathrm{y}}\right]_{\mathrm{n}}+\mathrm{HAuCl}_{4}-\mathrm{m}$ where $\mathrm{x}$ corresponds to the $\mathrm{pH}$ of the cationic solution, $\mathrm{y}$ is the $\mathrm{pH}$ of the anionic solution, and $\mathrm{n}$ represents the number of bilayers at the end of the process; the functionalized system with cysteine is represented by $\mathrm{Cys}+\mathrm{HAuCl}_{4}-\mathrm{m}$; and the samples without binder on the nanotube surfaces were labeled $\mathrm{TiO}_{2}+\mathrm{HAuCl}_{4}-\mathrm{m}$, where $\mathrm{m}$ corresponds to the $\mathrm{pH}$ of the gold solution.

Scanning electron microscopy (SEM) was performed using a Quanta 200 FEG coupled with an energy dispersive spectrometer (EDS). These made it possible to identify the nanotubes' morphology and the presence of gold nanoparticles.
X-ray diffraction (XRD) was performed using a Bruker diffractometer with $\mathrm{CuK} \alpha$ radiation, $2 \theta$ scanning from $20^{\circ}$ to $80^{\circ}$, and a step size of $0.02^{\circ}$ was used to identify the crystalline structure of samples and the different phases present.

Inductively coupled plasma mass spectrometry (ICP-MS) analysis was performed in order to determine the ratio of gold mass to $\mathrm{TiO}_{2}$. Thus, $15 \mathrm{mg}$ samples were used, and their dimensions were measured (width and length in $\mathrm{mm})$; next the samples were decomposed in a solution of $\mathrm{HNO}_{3}: \mathrm{HF}: \mathrm{HCl}(2: 1: 4 ; 3.5 \mathrm{~mL})$. After the solubilization, the volume was filled up to $50 \mathrm{~mL}$ for determination of $\mathrm{Au}$ amounts by ICP-MS.

Attenuated total reflectance Fourier-transform infrared (ATR-FTIR) were performed with Bruker Vertex 70 with diamond crystal and spectral resolution of $4 \mathrm{~cm}^{-1}$, which allowed to observe the calcination byproducts remaining in samples after heat treatment.

The Raman spectra were obtained with confocal Raman microscopy using an AFM Alpha 300 (Witec) with a $532 \mathrm{~nm}$ laser to identify the vibrational modes of $\mathrm{TiO}_{2}, \mathrm{Au}$ and the remaining organic byproducts. In order to provide the possibility of comparing the samples, the obtained spectra were normalized first to discuss.

Transmission electron microscopy (TEM) was performed with a Tecnai G2 $200 \mathrm{kV}$ (FEI) in a high vacuum, which allowed analysis of the size and distribution of nanoparticles after in situ reduction on the $\mathrm{TiO}_{2}$ nanotubes. Thus, it was possible to determine the magic numbers, providing the number of available actives sites on the nanoparticles surface.

The percentage of surface atoms was obtained by the average diameter of the nanoparticles, which was acquired previously by the TEM images. Additionally, it was possible to calculate the total number of atoms in a single particle $\left(\mathrm{G}_{\mathrm{i}}\right)$, from which the number of superficial atoms $\left(\mathrm{S}_{\mathrm{i}}\right)$ was estimated. The ratio of $\mathrm{S}_{\mathrm{i}}$ and $\mathrm{G}_{\mathrm{i}}$ consists in a relation between the superficial atoms and the total number of atoms in the particles ( $i=$ number of atoms), as shown in the following equations:

$\mathrm{G}_{\mathrm{i}}=\frac{10}{3} \mathrm{i}^{3}+5 \mathrm{i}^{2}+\frac{11}{3} \mathrm{i}+1, \mathrm{i} \geq 0$

$\mathrm{S}_{\mathrm{i}}=10 \mathrm{i}^{2}+2, \quad \mathrm{i} \geq 1$

Superficial atoms $(\%)=\frac{S_{i}}{G_{i}} \times 100$

Image-J/Fiji ${ }^{26}$ software was used to measure the nanoparticles and nanotubes diameter. OriginPro $8^{27}$ was used to plot the graphs. 


\section{Photocatalytic activity}

The samples were evaluated by hydrogen production. For that, samples were put into a quartz reactor and subjected to solar irradiation in a solar simulator (NewPort 69907, Xenon-Arc Lamp) with its potential calibrated for one sun. To check the amount of produced hydrogen gas, a $450 \mu \mathrm{L}$ sample was collected from the reactor every $30 \mathrm{~min}$ for $3 \mathrm{~h}$ and analyzed by gas chromatography (GC) using an Agilent 7820A with an HP-Plot molesieve capillary column, and a thermal conductivity detector (TCD) with argon as the drag gas. The irradiated sample area was approximately $3.0 \mathrm{~cm}^{2}$ for all photocatalytic tests, and the amount of hydrogen generated was divided by the sample area.

\section{Results and Discussion}

\section{Systems obtained and characterization}

Thin film self-assembly, formed through $\mathrm{LbL}$ deposition onto $\mathrm{TiO}_{2}$ nanotubes, was achieved using $\mathrm{pH}$ values of 7.5 and 3.5 for PAH and PAA, respectively. In this condition the $\mathrm{PAH}$ amine groups are partially deprotonated $\left(-\mathrm{NH}_{2}\right)$, and the chain is more highly interpenetrated; however, PAA is partially protonated $(-\mathrm{COOH})$, and its polymeric chain will be more stretched, ${ }^{22}$ leading to a nonlinear interaction between the polyelectrolyte chains. Polyelectrolytes $\mathrm{pH}$ values induced electrostatic interactions between the successive layers, generating an oppositely charged system, such as $\mathrm{COO}^{-}-\mathrm{NH}_{3}{ }^{+}$. Thus, the amine groups $\left(\mathrm{NH}_{3}{ }^{+}\right)$ neutralize the carboxylate groups $\left(\mathrm{COO}^{-}\right)$, promoting the decrease of free amine groups on the multilayer system.

Decorated $\mathrm{TiO}_{2}$ NT surfaces and cross-sectional morphologies can be observed in the TEM images (Figure 2). By analyzing Figures $2 \mathrm{~A}$ and $2 \mathrm{~B}$, it is possible to obtain an external tube diameter $(83 \pm 6 \mathrm{~nm})$ and inner diameter $(32 \pm 3 \mathrm{~nm})$ and part of the tube's length. Additionally, the adhesion of gold nanoparticles onto the nanotubes has been proven through the high resolution (HR)-TEM image (inset), whose plane of preferential orientation was determined from the interplanar spacing d using equation 4. Other TEM images are shown in the Supplementary Information section (Figure S1, SI section). Therefore, it was possible to identify the plane (220) corresponding to $\mathrm{d}=1.442$. This plane promotes a Bragg reflection at $2 \theta$ ca. $64^{\circ}$ when using $\mathrm{CuK} \alpha$ radiation in XRD analysis (Figure S2, SI section). The EDS graphics from both

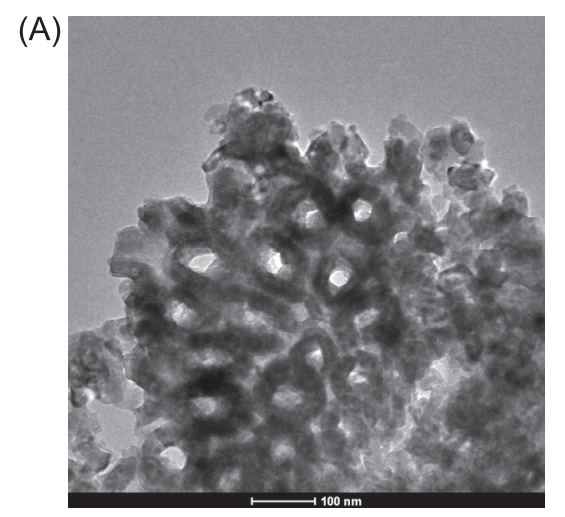

(B)
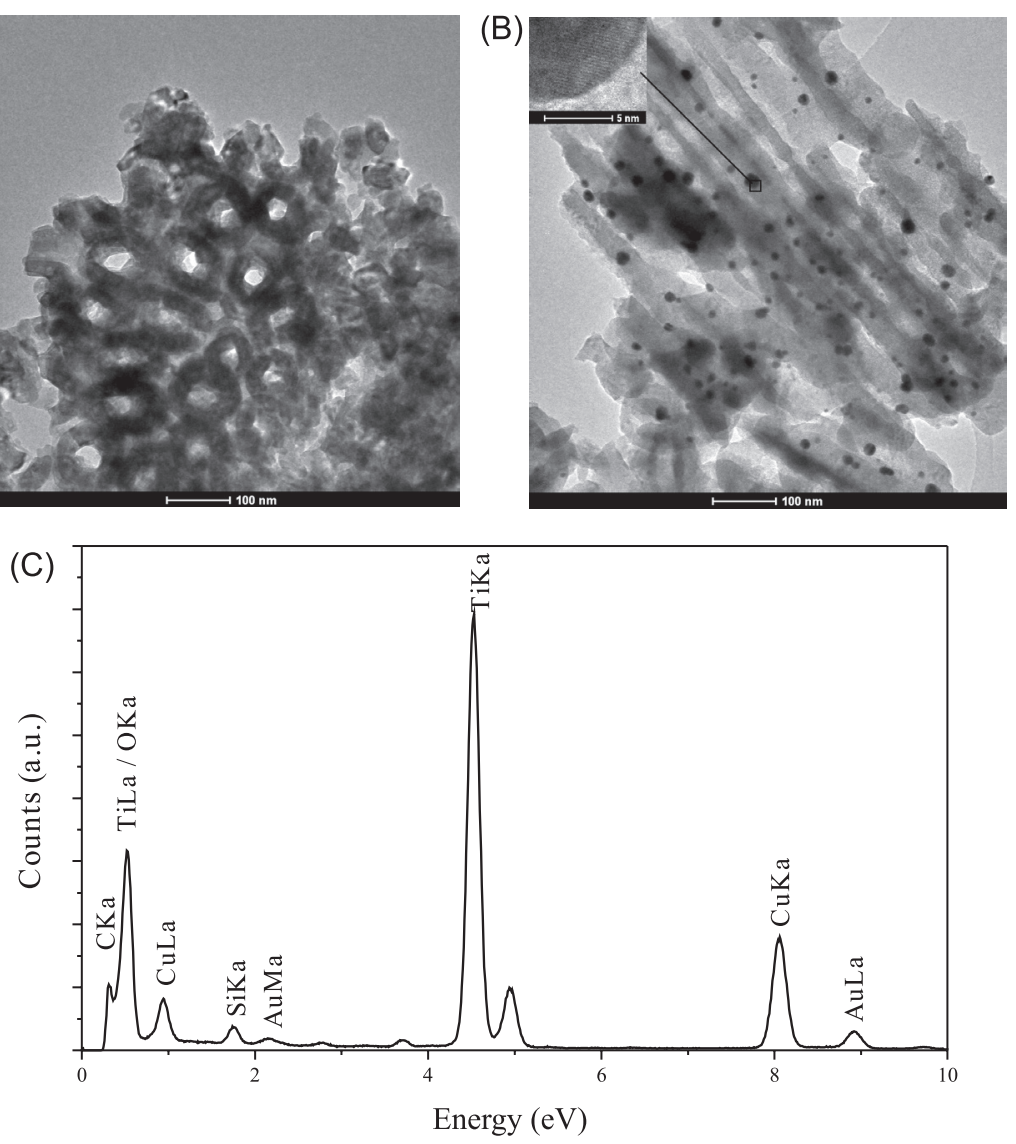

Figure 2. Representative TEM images of nanotubes (A) top-view, and (B) cross-view; and (C) EDS graph. 
the TEM (Figure 2C) and the SEM (Figure S3, SI section) confirm the presence of gold in the samples. Similar behaviors were observed for all the samples in the study.

$\frac{1}{\mathrm{~d}^{2}}=\frac{\mathrm{h}^{2}+\mathrm{k}^{2}+\mathrm{l}^{2}}{\mathrm{a}^{2}}$

where $\mathrm{h}, \mathrm{k}$ and $\mathrm{l}$ are the Index Miller.

Figure 3 shows the size distribution of nanoparticles for the different samples. It is notable that the size distribution is more homogeneous and has a Gaussian tendency, when the synthesis was achieved on LbL nanoreactors or when using cysteine instead when it is obtained directly on the nanotube's surface. It is suggested that these systems allow a better control of the size and format of the nanoparticles during reduction, once they promote the presence of preferential sites to nucleate gold nanoparticles, which differs from what occurs without binders. On the LbL systems, besides, the Gaussian tendency has a profile similar to a multimodal distribution,
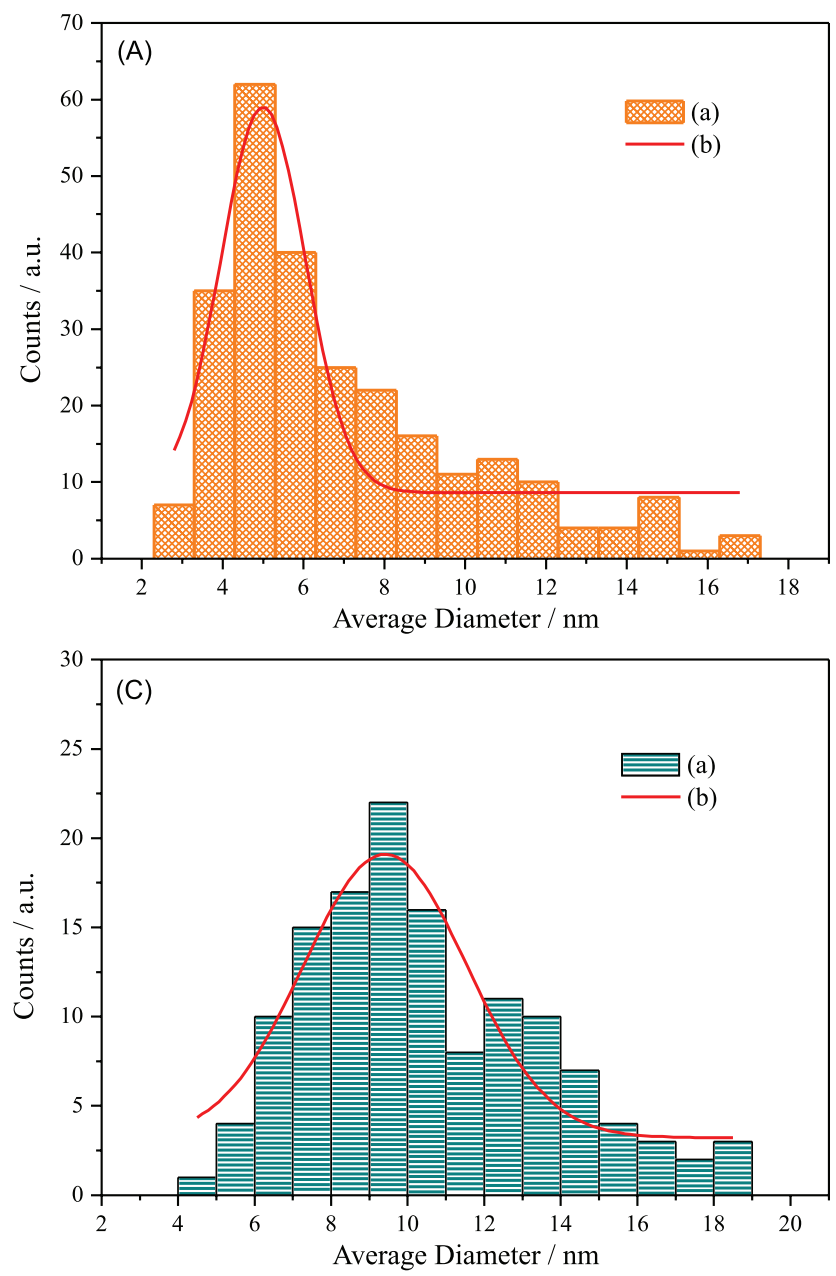

once the average diameter is not at the center of the Gaussian distribution-fit.

In Figure 3A, for the self-assembly thin film ended with PAA, the presence of three AuNPs size distributions was observed. A first, more expressive distribution occurred at approximately $5 \mathrm{~nm}$ in diameter, and a second and third were observed at approximately 11 and $15 \mathrm{~nm}$ in diameter, respectively. This behavior probably occurs due to the weak interaction of the gold complex ion with PAA, which is just an adsorption process, allowing some gold complex to interact with more internal layers of the self-assembled system, and consequently they bind to the amine groups from PAH.

On a second approach, when the nanoparticles were obtained after gold salt adsorption on systems ending with PAH (Figure 3B), the gold complex could interact with amine groups, and the nanoparticles size distribution was more homogenous due to the binder controlling its growth. When nanoparticles were reduced into LbL systems, the nucleation occurred preferentially on amine
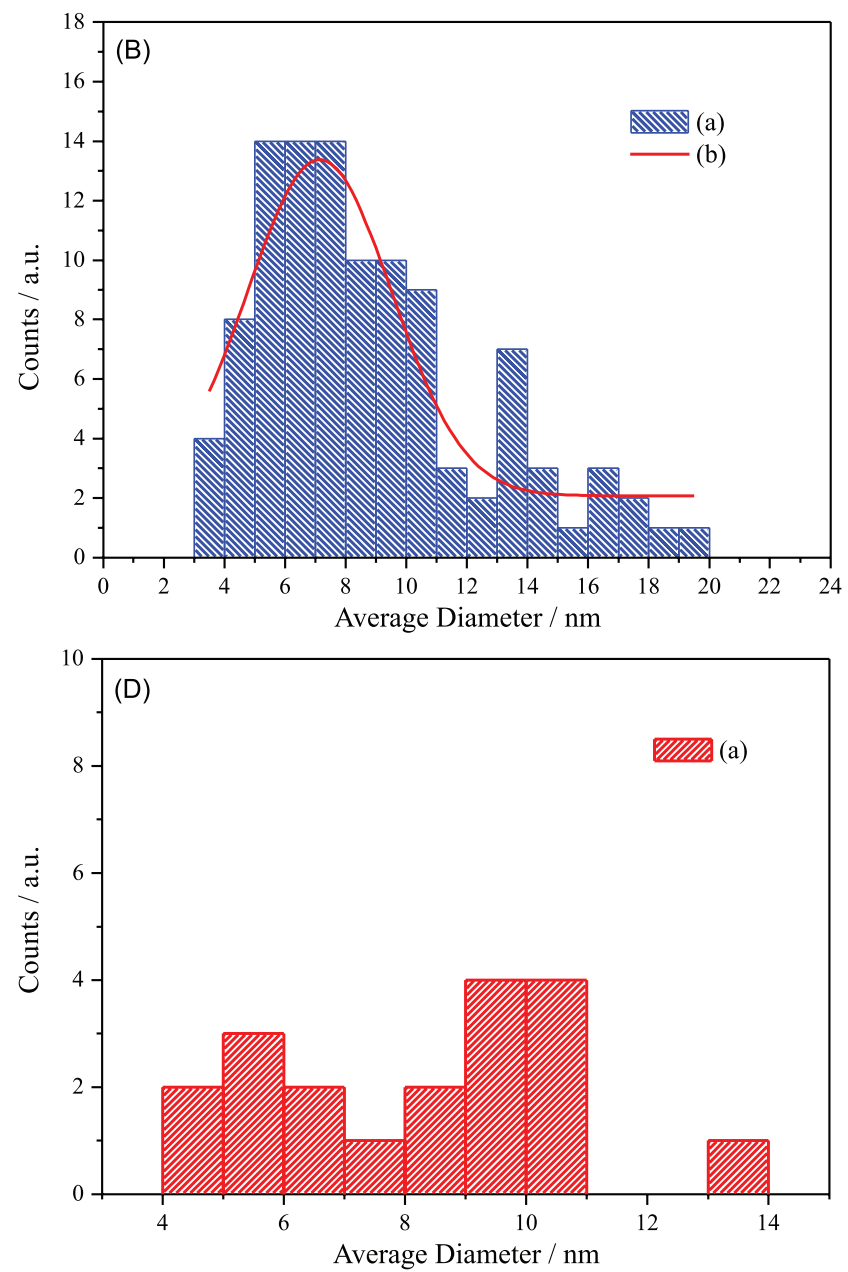

Figure 3. (a) Frequency distribution of nanoparticles diameter for samples (A) $\left[\mathrm{PAH}_{7.5} / \mathrm{PAA}_{3.5}\right]_{5}+\mathrm{HAuCl}_{4}-2.3,(\mathrm{~B})\left[\mathrm{PAH}_{7.5} / \mathrm{PAA}_{3.5}\right]_{5.5}+\mathrm{HAuCl}_{4}-2.3$, (C) $\mathrm{Cys}+\mathrm{HAuCl}_{4}-2.3$, and (D) $\mathrm{NTs}+\mathrm{HAuCl}_{4}-2.3$; (b) Gaussian fit of frequency for both samples. 
groups; this is a function of the $\mathrm{pH}$ of both polyelectrolytes and gold salt, which can modify the availability of amine groups. ${ }^{23}$ Moreover, the growth is controlled by the chain conformations as a result of using a molecule with functional groups able to bind to nanoparticles, which stabilizes and functionalizes them.

Next, with the use of cysteine (Figure 3C) it was possible to obtain nanoparticles with approximately $8 \mathrm{~nm}$ diameters that were homogeneously distributed around the average, which was expected by the presence of thiol groups during reduction; this presents great chemical affinity for gold and could act as directors to nucleation. It was achieved using cysteine at $\mathrm{pH}$ 6.0, upon which the carboxylate groups can interact with the $\mathrm{TiO}_{2}$ carboxylate groups, while the amine and thiol groups are widely attracted to and bind to gold, which enables its uniform distribution. ${ }^{28}$

Finally, a less-uniform size distribution was observed on the system without binders (Figure 3D), where two big populations (approximately 5 and $11 \mathrm{~nm}$ ) were formed due to the absence of control during the nucleation and growth steps. Due to the low nanoparticles content on this system a poor count number was obtained.

From average diameters of the nanoparticles determined by the TEM images, we could proceed to calculate the surface-active sites on the samples (Table 1). The presence of a great number of surface atoms is an important factor, but it does not determine the nanoparticles' efficiency in applications such as photocatalysis, as both the shape and number of particles can affect their performance. For this reason, despite the $\left[\mathrm{PAH}_{7.5} / \mathrm{PAA}_{3.5}\right]_{5}+\mathrm{HAuCl}_{4}-2.3$ sample presented the biggest surface atom ratio, other factors can affect the sample's response to photochemical analysis.

The quantification of the gold/catalyst relative amounts was achieved through ICP, whose results are shown in Table 2. These results clearly showed a variation in the amount of gold according to the binder and gold salt $\mathrm{pH}$. According to Mayya et al..$^{29}$ gold nanoparticle adsorption to charged polyelectrolytes can be achieved with gold salt concentration ranging from 1 to $20 \mathrm{mmol} \mathrm{L}^{-1}$. In this way, the $5 \mathrm{mmol} \mathrm{L}^{-1}$ used in this work is expected to be sufficient to load gold onto the samples with LbL. Due to the polyelectrolytes chain conformation and effective adsorptions, as discussed before, a large amount of nanoparticle adsorption on the LbL systems is expected, especially on amine groups. In this way, the sample $\left[\mathrm{PAH}_{7.5} / \mathrm{PAA}_{3.5}\right]_{5.5}$ that was created adsorbs a larger amount of gold than the system ending with PAA. Additionally, photolytic reactions during gold reduction induces more active sites to gold adsorption on amine groups, which generates a smaller crystallite size.

When self-assembly systems are exposed to an acid medium with a $\mathrm{pH}>2.5$, a smaller concentration of amine groups will be available to bind with the gold ion complex, hence a smaller amount of gold salt could be reduced. On the other hand, at $\mathrm{pH}<2.5$ amine groups will be largely protonated, which leads to a higher number of $-\mathrm{NH}_{3}{ }^{+}$available to interact with the gold ions complexes, as observed by Rubner and co-workers ${ }^{23}$ On their studies on the effect of extreme $\mathrm{pH}$ conditions, it was perceived that layers were removed as a consequence of the acid media. ${ }^{23}$ Thus, the LbL system samples were studied in more detail when used with gold salts at $\mathrm{pH} 2.3$, since less efficiency is expected with $\mathrm{pH} 1.8$ and 2.7. Therefore, the self-assembly system that ends with PAH and those with cysteine were expected to be those with the highest number of gold nanoparticles deposited, and this was demonstrated by ICP-MS analysis. In addition, due to the partially coiled structure of PAH/PAA, it is expected that multilayer systems allow a better distribution of the nanoparticles on the surface of the nanotubes.

In addition to promoting $\mathrm{TiO}_{2}$ anatase phase formation, the heat treatment acts to remove the polyelectrolyte or cysteine from the system. ${ }^{30}$ This can be observed by ATR-FTIR analysis (Figure 4). For the system Cys $+\mathrm{HAuCl}_{4}-\mathrm{m}$, at $\mathrm{m}=1.8,2.3,2.7$, it can be noticed that almost all organic matter was eliminated after heat treatment as seen in the spectra (B). For Cys $+\mathrm{HAuCl}_{4}-2.7$ arrangement, it is observed a broad band in $2000-1200 \mathrm{~cm}^{-1}$,

Table 1. Surface atoms calculated for samples using $\mathrm{HAuCl}_{4}-2.3$

\begin{tabular}{lcccc}
\hline Sample & $\begin{array}{c}\text { NPs average } \\
\text { diameter } / \mathrm{nm}\end{array}$ & $\mathrm{G}_{\mathrm{i}}{ }^{\mathrm{a}}$ & $\mathrm{S}_{\mathrm{i}}^{\mathrm{b}}$ & $\mathrm{S}_{\mathrm{i}} / \mathrm{G}_{\mathrm{i}}^{\mathrm{c}} / \%$ \\
\hline$\left[\mathrm{PAH}_{7.5} / \mathrm{PAA}_{3.5}\right]_{5}+\mathrm{HAuCl}_{4}-2.3$ & 6.3 & 7792.51 & 1630.97 & 20.93 \\
{$\left[\mathrm{PAH}_{7.5} / \mathrm{PAA}_{3.5}\right]_{5.5}+\mathrm{HAuCl}_{4}-2.3$} & 7.1 & 11222.54 & 2098.70 & 18.70 \\
$\mathrm{Cys}_{\mathrm{HAuCl}}-2.3$ & 10.7 & 37819.56 & 4826.74 & 12.77 \\
$\mathrm{TiO}_{2}+\mathrm{HAuCl}_{4}-2.3$ & 5.7 & 5716.55 & 1315.32 & 23.01 \\
& 9.8 & 29036.26 & 4030.05 & 13.88 \\
\hline
\end{tabular}

${ }^{a}$ Number of atoms in the nanoparticle volume; ${ }^{b}$ number of surface atoms in the nanoparticle; ${ }^{c}$ percentage of surface atoms related to the total atoms of the nanoparticle. NP: nanoparticles; Cys: cycsteine; PAH: poly(allylamine hydrochloride); PAA: poly(acrylic acid). 
possibly related with organic ligand remained on NTs surface associated to an increase of cysteine-gold complex adhesion to $\mathrm{TiO}_{2}$ lattice, since this system has the highest

Table 2. Gold quantification by ICP and hydrogen production for all samples studied

\begin{tabular}{|c|c|c|}
\hline Sample & $\begin{array}{c}\mathrm{Au} / \\
\left(\mathrm{ng} \mathrm{mm}^{-2}\right)\end{array}$ & $\begin{array}{l}\text { Hydrogen } \\
\text { production / } \\
\left(\mu \mathrm{mol} \mathrm{cm} \mathrm{cm}^{-2}\right)\end{array}$ \\
\hline$\left[\mathrm{PAH}_{7.5} / \mathrm{PAA}_{3.5}\right]_{5}+\mathrm{HAuCl}_{4}-2.3$ & $172 \pm 31$ & 0.21 \\
\hline$\left[\mathrm{PAH}_{7.5} / \mathrm{PAA}_{3.5}\right]_{5.5}+\mathrm{HAuCl}_{4}-2.3$ & $253 \pm 20$ & 0.80 \\
\hline $\mathrm{Cys}+\mathrm{HAuCl}_{4}-1.8$ & $118 \pm 17$ & 1.16 \\
\hline $\mathrm{Cys}+\mathrm{HAuCl}_{4}-2.3$ & $39 \pm 6$ & 0.50 \\
\hline $\mathrm{Cys}+\mathrm{HAuCl}_{4}-2.7$ & $211 \pm 34$ & 2.02 \\
\hline $\mathrm{TiO}_{2}+\mathrm{HAuCl}_{4}-1.8$ & $4.6 \pm 0.9$ & 0.11 \\
\hline $\mathrm{TiO}_{2}+\mathrm{HAuCl}_{4}-2.3$ & $80 \pm 12$ & 0.22 \\
\hline $\mathrm{TiO}_{2}+\mathrm{HAuCl}_{4}-2.7$ & $17 \pm 3$ & 0.12 \\
\hline
\end{tabular}

PAH: poly(allylamine hydrochloride); PAA: poly(acrylic acid); Cys: cycsteine.

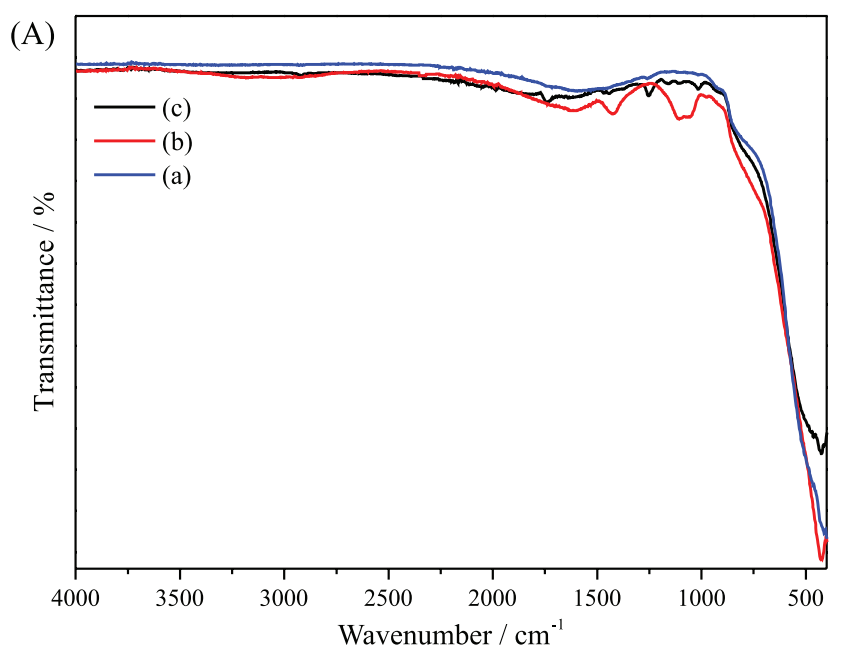

amount of gold nanoparticles (shown by ICP-MS) ${ }^{31}$ In what appears to be direct consequence of gold load deposited on NTs, more gold woks as capping system, lowering the elimination of organic binders during heat treatment. For the spectra of the other two systems with cysteine (e.g., Cys $+\mathrm{HAuCl}_{4}-2.3$ and $\mathrm{Cys}+\mathrm{HAuCl}_{4}-1.8$ ) any binder characteristic peak could be addressed. In spite of that, for $\mathrm{pH} 2.3$, Ti-O stretching band in $554 \mathrm{~cm}^{-1}$ were more pronounced and can be assigned to $\mathrm{TiO}_{2}$ anatase phase, indicating more effective elimination of organic ligands after calcination. ${ }^{32}$ This corroborates with the thesis that a higher gold load acts as capping to the organic binders.

In the spectrum (a) of Figure $4 \mathrm{C}\left(\left[\mathrm{PAH}_{7.5} / \mathrm{PAA}_{3.5}\right]_{5.5}\right)$, low intensity bands of carboxylic acid remaining on $\mathrm{TiO}_{2}$ surface are more observable, $\mathrm{C}=\mathrm{O}\left(v=1740 \mathrm{~cm}^{-1}\right)$ and $\mathrm{C}-\mathrm{O}$ $\left(v=1240 \mathrm{~cm}^{-1}\right),{ }^{22}$ both stretching bands. PAH-terminated system has more gold nanoparticles adhered to the $\mathrm{TiO}_{2}$ surface (as shown by ICP-MS) due to more interactions with $-\mathrm{NH}_{3}{ }^{+}$groups and, again, the AuNPs appears to act

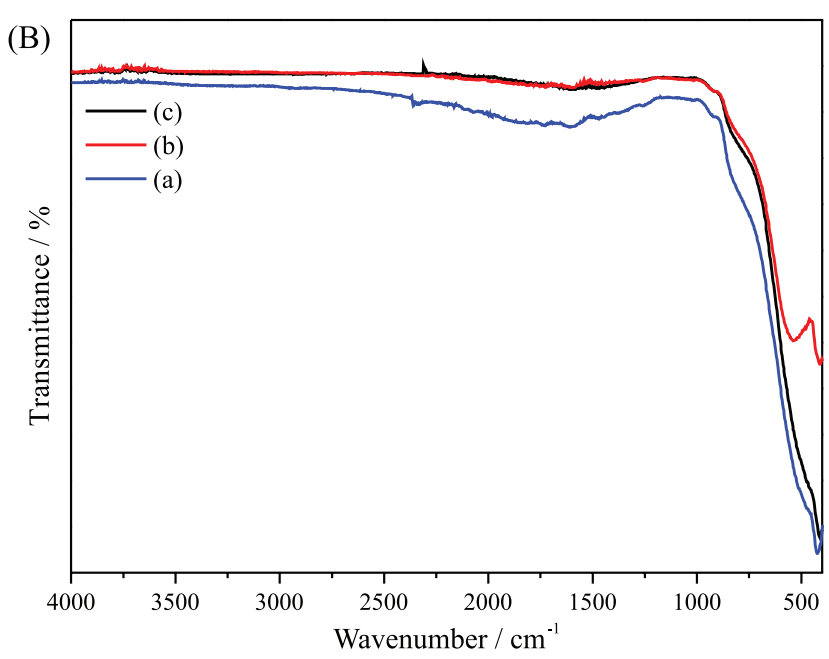

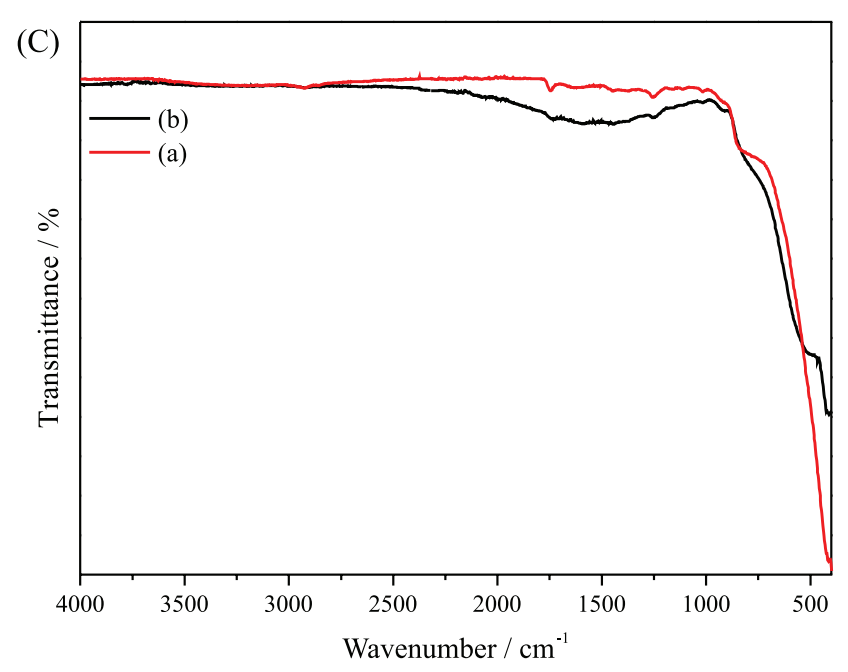

Figure 4. FTIR analysis for: (A) $\mathrm{TiO}_{2}+\mathrm{HAuCl}_{4}-\mathrm{m}, \mathrm{m}=2.7$ (a), 2.3 (b), and 1.8 (c); (B) Cys $+\mathrm{HAuCl}_{4}-\mathrm{m}, \mathrm{m}=2.7$ (a), 2.3 (b), and 1.8 (c); and (C) [PAH7.5/ PAA3.5]n $+\mathrm{HAuCl}_{4}-2.3, \mathrm{n}=5.5$ (a) and 5 (b). 
as a capping system for organic matter adhered to the crystal lattice of NTs. For $\left[\mathrm{PAH}_{7.5} / \mathrm{PAA}_{3.5}\right]_{5}$ system, it is possible to observe $\mathrm{TiO}_{2}$ anatase contribution in the range of $400-800 \mathrm{~cm}^{-1} .^{33}$

In $\mathrm{TiO}_{2}+\mathrm{HAuCl}_{4}$ spectra at $\mathrm{pH} 1.8$ and 2.7 low intensity bands are observable again, showing almost all the organic matter from nanotubes reaction formation was eliminated after heat treatment. ${ }^{32}$ For $\mathrm{pH} 1.8$, carboxylic acid bands are still observed, and this reflects the low adhesion of gold nanoparticles, since with more $-\mathrm{COOH}$ remaining groups from nanotubes synthesis fewer carboxylate sites were available for adhesion with gold. However, for $\mathrm{pH} 2.3$, band stretching was observed at $1104 \mathrm{~cm}^{-1}$ for $\mathrm{C}-\mathrm{O}$ groups, and there was symmetric stretching of carboxylate group at $1428 \mathrm{~cm}^{-1}, 33,34$ which demonstrates that at this $\mathrm{pH}$ these groups were available in the system generating more sites
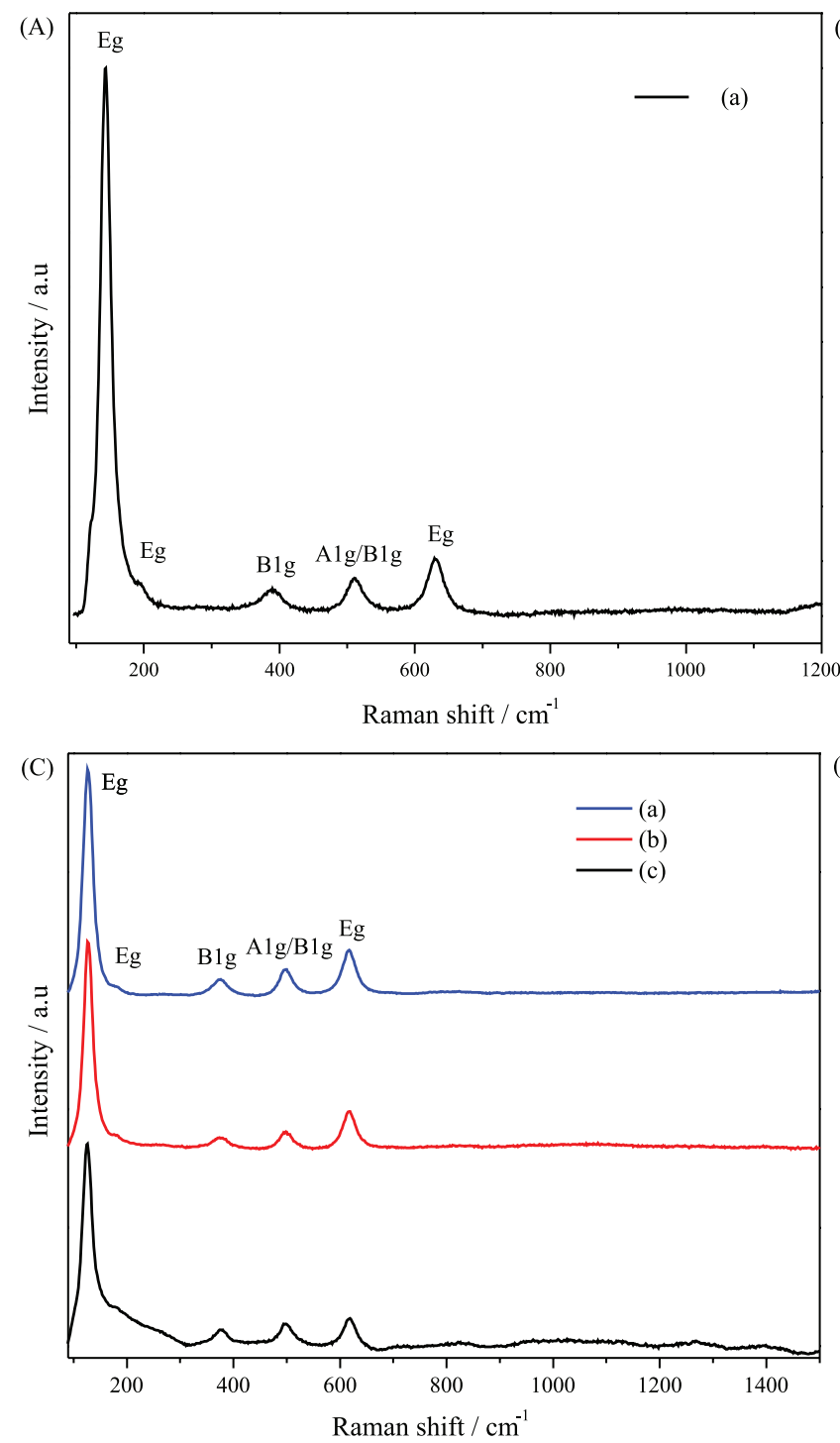

for gold nanoparticle adsorption than in the other samples of $\mathrm{TiO}_{2} / \mathrm{Au}$, as was confirmed by ICP-MS.

The structural features were studied by Raman spectroscopy (Figure 5). For all the systems the characteristic active modes of the crystalline anatase $\mathrm{TiO}_{2}$ are observed in the spectra at: $\mathrm{E}_{\mathrm{g}}\left(124-140 \mathrm{~cm}^{-1}\right)$, $\mathrm{E}_{\mathrm{g}}\left(180 \mathrm{~cm}^{-1}\right), \mathrm{B}_{1 \mathrm{~g}}\left(376-388 \mathrm{~cm}^{-1}\right), \mathrm{A}_{1 \mathrm{~g}} / \mathrm{B}_{1 \mathrm{~g}}\left(498 \mathrm{~cm}^{-1}\right)$, and $\left.\mathrm{E}_{\mathrm{g}}\left(618 \mathrm{~cm}^{-1}\right)\right)^{33,35}$ The interaction of the AuNPs surface displaces the characteristic modes of $\mathrm{TiO}_{2}$ as a function of bond formation with molecules on nanotubes surface. This effect is less pronounced in the $\mathrm{TiO}_{2}+\mathrm{HAuCl}_{4}-1.8$, with profile similar to pure anatase, which is corroborated by the ICP-MS (shown below), given a lesser amount of AuNPs deposited on this sample. This result suggests an almost-full elimination of organic compounds after heat treatment, as seen in the ATR-FTIR. The spectra for $\mathrm{TiO}_{2}+\mathrm{HAuCl}_{4}-2.3$
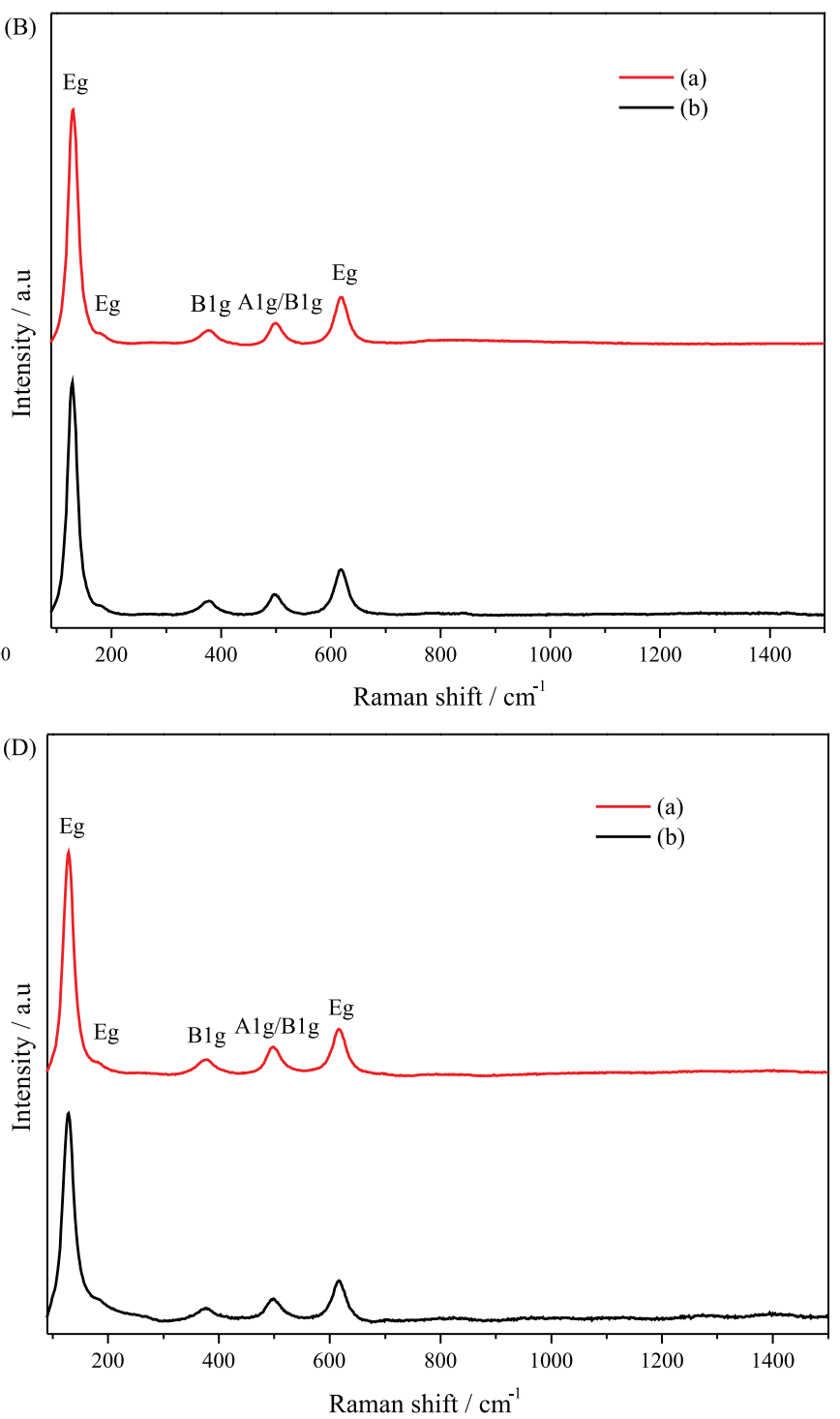

Figure 5. Raman analysis for: (A) $\mathrm{TiO}_{2}+\mathrm{HAuCl}_{4}-1.8$; (B) $\mathrm{TiO}_{2}+\mathrm{HAuCl}_{4}-\mathrm{m}, \mathrm{m}=2.7$ (a), and 2.3 (b); (C) Cys $+\mathrm{HAuCl}_{4}-\mathrm{m}, \mathrm{m}=2.7$ (a), 2.3 (b), and 1.8 (c); and (D) $\left[\mathrm{PAH}_{7.5} / \mathrm{PAA}_{3.5}\right]_{\mathrm{n}}+\mathrm{HAuCl}_{4}-2.3, \mathrm{n}=5.5$ (a), and 5 (b). 
and $\mathrm{TiO}_{2}+\mathrm{HAuCl}_{4}-2.7$ presented similar features due to the low amount of AuNPs that was not enough to cause significant change on $\mathrm{TiO}_{2}$ lattice.

In the Cys $+\mathrm{HAuCl}_{4}-1.8$ system, the peak broadening at the $\mathrm{E}_{\mathrm{g}}\left(180 \mathrm{~cm}^{-1}\right)$ and $\mathrm{B}_{\mathrm{gg}}\left(376-388 \mathrm{~cm}^{-1}\right)$ modes is more intense among samples with cysteine. Additionally, a weak widening from $1000-1400 \mathrm{~cm}^{-1}$ can be observed, which indicates the effect of AuNPs interaction with $\mathrm{TiO}_{2}$ nanotubes crystalline lattice after heat treatment as a change of chemical media. ${ }^{33}$ On the other hand, for $\mathrm{Cys}+\mathrm{HAuCl}_{4}-2.7$, which had a higher gold load, a slight shift with regards to the characteristic modes of $\mathrm{TiO}_{2}$ was observed when compared with $\mathrm{Cys}+\mathrm{HAuCl}_{4}-1.8$. This behavior can be attributed to a uniform distribution of AuNPs, who minimize the crystal lattice distortions caused by the electronic interactions between $\mathrm{Au}$ and $\mathrm{TiO}_{2}$ after calcination, as discussed in ATR-FTIR spectra. A similar behavior was observed for Cys $+\mathrm{HAuCl}_{4}-2.3$. The NPs' growth did not occur directly on the NTs' surface, since this molecule has thiol group sites; these sites have strong affinity with gold through soft-soft interaction, so they are likely sites for nucleation and growth of gold nanoparticles. For this system $\mathrm{pH}$ is also a key aspect, but it needs further investigation in order to understand its behavior.

In the spectra obtained for the LbL systems, peak broadening for $\mathrm{E}_{\mathrm{g}}$ and $\mathrm{B}_{1 \mathrm{~g}}$ modes is marked for the PAA-terminated sample $\left(\left[\mathrm{PAH}_{7.5} / \mathrm{PAA}_{3.5}\right]_{5}\right)$. Thus, this LbL has few $-\mathrm{NH}_{3}{ }^{+}$groups on the surface layers regarding to $\left[\mathrm{PAH}_{7.5} / \mathrm{PAA}_{3.5}\right]_{5.5}$. It can lead to a less uniform distribution of AuNPs; then, the interaction with $-\mathrm{COO}^{-}$groups would be internally preferential in LbL. After the thermal treatment, the peak broadening of the modes is increased due to the electronic interaction of $\mathrm{Au}$ with $\mathrm{TiO}_{2}$. In the PAH-terminated sample $\left(\left[\mathrm{PAH}_{7.5} / \mathrm{PAA}_{3.5}\right]_{5.5}\right)$, with more $-\mathrm{NH}_{3}{ }^{+}$groups, the distribution of AuNPs is larger and more uniform, causing less distortion of crystalline modes of $\mathrm{TiO}_{2}$ after the heat treatment. In these cases, it is important to highlight that soft-soft/hard-hard interactions are not significant for gold deposition in the system due to the ionic layer structure of $\mathrm{LbL}$, which is related to the $\mathrm{pH}$ of the solutions used, as discussed by Choi and Rubner. ${ }^{22}$

According to previous results, the suggested mechanism of $\mathrm{AuCl}_{4}{ }^{-}$photolysis on $\mathrm{LbL}$ systems is presented below in reactions $5-10 .{ }^{36} \mathrm{~A}$ similar approach is expected when using cysteine as a function of the thiol groups, which for $\mathrm{NTs}+\mathrm{HAuCl}_{4}$ samples occurs by way of the remaining groups for nanotubes synthesis.

$$
\begin{aligned}
& \mathrm{AuCl}_{4}^{-} \stackrel{\text { hv }}{\leftrightarrow} \mathrm{AuCl}_{4}^{-*} \leftrightarrow \mathrm{AuCl}_{3}^{-}+\mathrm{Cl}^{-} \\
& 2 \mathrm{Cl}^{\circ}+\mathrm{COOH}+\mathrm{NH}_{3}^{+} \rightarrow 2 \mathrm{HCl}+\mathrm{COO}^{-}+\mathrm{NH}_{2}^{*} \\
& 2 \mathrm{Au}^{3+}+\mathrm{COO}^{\circ}+\mathrm{NH}_{2}^{-} \rightarrow \mathrm{CO}_{2}+2 \mathrm{Au}^{2+}+\mathrm{NH}_{2}
\end{aligned}
$$

$$
\begin{aligned}
& 2 \mathrm{Au}^{2+} \rightarrow \mathrm{Au}^{3+}+\mathrm{Au}^{+} \\
& -\mathrm{NH}_{2}^{-}+\mathrm{Au}^{+} \rightarrow \mathrm{Au}^{0}-\mathrm{NH}_{2} \\
& \mathrm{nAu}{ }^{0} \rightarrow \mathrm{AuNPs}
\end{aligned}
$$

\section{Hydrogen production}

The photocatalytic properties of the samples were characterized by hydrogen production. Table 2 shows the amounts of hydrogen gas obtained after $180 \mathrm{~min}$ for different samples with AuNPs. In general, the photocatalytic activity of $\mathrm{TiO}_{2}$ NTs obtained by the anodization process depends on the type of catalysts used. ${ }^{37}$

When the obtained results are analyzed in terms of samples using different polyelectrolytes and without binders, those with polyelectrolyte showed a lower hydrogen production than was expected, since they have a greater amount of gold in the system. However, these samples were more photoactive than those without binders, which can be related to a greater amount of AuNPs.

When samples with cysteine and without binders were analyzed, an opposite behavior is demonstrated in terms of the AuNPs precursor $\mathrm{pH}$. The Cys $+\mathrm{HAuCl}_{4}-2.7$ system showed great result, photogenerating $2.02 \mu \mathrm{mol} \mathrm{cm} \mathrm{cm}^{-2}$ of hydrogen. On the other hand, for the samples with cysteine, the $\mathrm{pH} 2.3$ is the less efficient; however, without binders, $\mathrm{pH} 2.3$ is the most efficient, and this corroborates the ICP results. In other words, the number of nanoparticles in the system plays an important role in improving the photocatalytic efficiency. These results indicate that the charge transfer mechanisms in the samples with polyelectrolyte occur in a different way than what was observed in the other samples.

The curves obtained on hydrogen production for more active samples are shown in Figure 6, as well as the curves for $\mathrm{TiO}_{2} \mathrm{NTs}$ as prepared and after heat treatment. The results showed that the presence of an anatase phase plays an important role in the creation of a preferential direction for the electron transport, which increases the time for holeelectron recombination. Comparing the results of the only heat-treated $\mathrm{TiO}_{2}$-sample with the samples containing gold, it can be seen how the use of a cocatalysts is important, and the hydrogen production efficiency improves by at least 2-fold when they are used.

The presence of a gold-like cocatalyst increases the hydrogen production efficiency in different ways, which include the absorption of visible radiation, through SPR, or by the capture of photogenerated electrons. ${ }^{38,39}$ One of these effects will overlap with another depending on the type of radiation used; that is, the efficiency of the system can be decreased when there is the simultaneous presence of the ultraviolet and visible light. Regarding this approach, 
the photocatalytic efficiency of the samples is related to the amount of AuNPs and its distribution over the nanotubes surface.

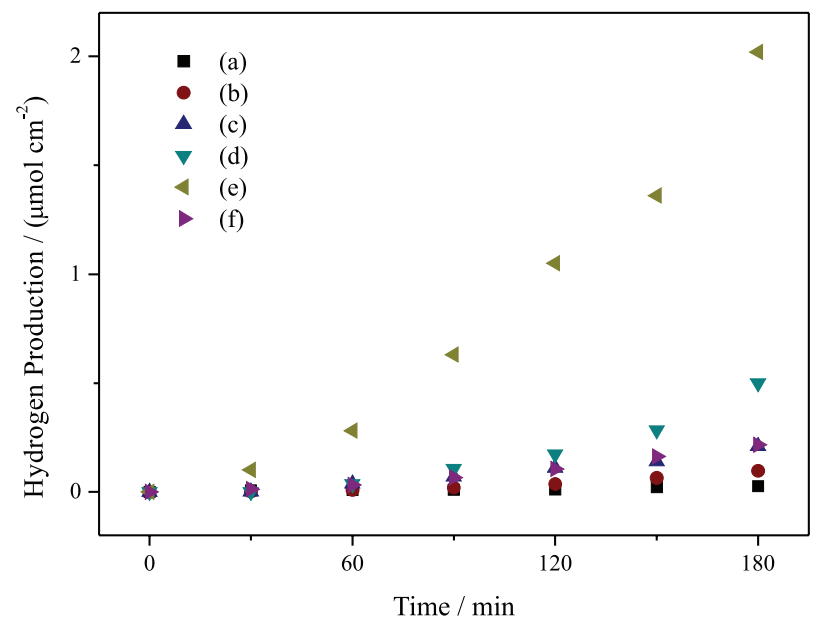

Figure 6. Hydrogen production for the most active samples compared with $\mathrm{TiO}_{2}$ NTs as synthesized (a) and heat treated (b). The other samples are identified as: (c) $\left[\mathrm{PAH}_{7.5} / \mathrm{PAA}_{3.5}\right]_{5}+\mathrm{HAuCl}_{4}-2.3$, (d) $\left[\mathrm{PAH}_{7.5} / \mathrm{PAA}_{3.5}\right]_{5.5}+$ $\mathrm{HAuCl}_{4}-2.3$, (e) Cys $+\mathrm{HAuCl}_{4}-2.7$, and (f) $\mathrm{TiO}_{2}+\mathrm{HAuCl}_{4}-2.3$.

In fact, the results obtained in this work are in good agreement with others presented in the literature. In this context, our results presented an increase in hydrogen production by up of 20 times in regards to the matrix $\left(\mathrm{TiO}_{2}\right)$. On the other hand, Zhang et al. ${ }^{40}$ reported an increase in hydrogen production of 3 times for their sample when compared to $\mathrm{TiO}_{2} \mathrm{NTs}$; and similar results to those reported here were verified by Carrasco-Jaim et $a l .{ }^{41}$ and Wang and $\mathrm{Li}^{42}$ In this approach, the systems obtained on this work present great power for the design of nanostructured photocatalytic reactors for hydrogen generation. These results open an important path for the technological development applied to $\mathrm{H}_{2}$ production. The enhancement of the advantage of our system regards to other available until the moment is that it can be obtained from environmentally friendly materials.

\section{Conclusions}

In summary, the effect of active functional groups cationic $\left(\mathrm{PAH}-\mathrm{NH}_{3}\right.$ ), anionic (PAA - $\left.\mathrm{COOH}\right)$, and both (cysteine - presenting $\mathrm{COOH}, \mathrm{NH}_{3}$, and $\mathrm{SH}$ ) - to attach gold ion (nanoparticles precursor) as a function of the $\mathrm{pH}$ of gold salt was studied. FTIR and Raman analysis elucidated the behavior of different binders with a $\mathrm{TiO}_{2} \mathrm{NTs}$ surface, enabling us to propose a mechanism of $\mathrm{AuCl}_{4}{ }^{-}$photolysis. Based on the characterization results, the $\mathrm{Cys}+\mathrm{HAuCl}_{4}-2.7$ system obtained gold nanoparticles with exceptional morphologies (approximately $8 \mathrm{~nm}$ of diameter) and excellent gold nanoparticle absorption $\left(211 \mathrm{ng} \mathrm{mm}^{-2}\right)$ on the $\mathrm{TiO}_{2} \mathrm{NT}$ surface. This was achieved due to the thiol groups sites of cysteine, which has great affinity with gold through soft-soft interaction, making these sites likely for nucleation and growth of gold nanoparticles. As result, this system photogenerated $2.02 \mu \mathrm{mol} \mathrm{cm} \mathrm{cm}^{-2}$ of hydrogen after $180 \mathrm{~min}$ under solar irradiation. Thus, $\mathrm{Cys}+\mathrm{HAuCl}_{4}-2.7$ has wide potential to be an efficient material for single catalyst water splitting, since it combines crystallinity, morphology and amount of cocatalyst, with increasing light absorption and consequently $\mathrm{H}_{2}$ production.

\section{Supplementary Information}

Supplementary data (XRD, SEM) are available free of charge at http://jbcs.sbq.org.br as PDF file.

\section{Acknowledgments}

The authors thank to technical support of CETENE (Centro de Tecnologias Estratégicas do Nordeste). They also thank to FACEPE (Fundação de Apoio à Pesquisa do Estado de Pernambuco), CAPES (Coordenação de Aperfeiçoamento Pessoal de Nível Superior), and CNPq (Conselho Nacional de Desenvolvimento Científico e Tecnológico) for financial support and grants.

\section{References}

1. Yuan, Y. P.; Ruan, L. W.; Barber, J.; Joachim Loo, S. C.; Xue, C.; Energy Environ. Sci. 2014, 7, 3934.

2. Ghori, M. Z.; Veziroglu, S.; Henkel, B.; Vahl, A.; Polonskyi, O.; Strunskus, T.; Faupel, F.; Aktas, O. C.; Sol. Energy Mater. Sol. Cells 2018, 178, 170.

3. Kumar, M.; Kumar, A.; Renew. Sustain. Energy Rev. 2017, 78, 554.

4. International Energy Agency; Hydrogen Production and Storage - R\&D Priorities and Gaps; IEA Publications: Paris, France, 2006.

5. Fujishima, A.; Honda, K.; Nature 1972, 238, 37.

6. Gholipour, M. R.; Dinh, C. T.; Bélandb, F.; Do, T. O.; Nanoscale 2015, 7, 8187.

7. Nakata, K.; Fujishima, A.; J. Photochem. Photobiol., C 2012, $13,169$.

8. Liao, C. H.; Huang, C. W.; Wu, J. C. S.; Catalysts 2012, 2, 490.

9. Marschall, R.; Adv. Funct. Mater. 2014, 24, 2421.

10. Ahmad, H.; Kamarudin, S. K.; Minggu, L. J.; Kassim, M.; Renew. Sustain. Energy Rev. 2015, 43, 599.

11. Wang, S. P.; Zhang, T. Y.; Wang, X. Y.; Zhang, S. M.; Wang, S. R.; Huang, W. P.; Wu, S. H.; J. Mol. Catal. A: Chem. 2007, $272,45$. 
12. Su, R.; Tiruvalam, R.; Logsdail, A. J.; He, Q.; Downing, C. A.; Jensen, M. T.; Dimitratos, N.; Kesavan, L.; Wells, P. P.; Bechstein, R.; Jensen, H. H.; Wendt, S.; Catlow, C. R. A.; Kiely, C. J.; Hutchings, G. J.; Besenbacher, F.; ACS Nano 2014, 8, 3490 .

13. Lee, Y. K.; Lee, H.; Lee, C.; Hwang, E.; Park, J. Y.; J. Phys.: Condens. Matter 2016, 28, 254006.

14. Primo, A.; Corma, A.; Garciá, H.; Phys. Chem. Chem. Phys. 2011, 13, 886 .

15. Marchal, C.; Behr, M.; Vigneron, F.; Caps, V.; Keller, V.; New J. Chem. 2016, 40, 4428.

16. Li, C.; Monti, S.; Agren, H.; Carravetta, V.; Langmuir 2014, 30, 8819.

17. Dal'Acqua, N.; Mattos, A. B. D.; Krindges, I.; Pereira, M. B.; Barud, H. D. S.; Ribeiro, S. J. L.; Duarte, G. C. S.; Radtke, C.; Almeida, L. C.; Giovanela, M.; Crespo, J. D. S.; J. Phys. Chem. C 2015, 119, 340.

18. Srivastava, S.; Kotov, N. A.; Acc. Chem. Res. 2008, 41, 1831.

19. Shiratori, S. S.; Rubner, M. F.; Macromolecules 2000, 33, 4213.

20. Veerbeek, J.; Reinhoudt, D. N.; Huskens, J. In Multilayer Thin Films: Sequential Assembly of Nanocomposite Materials; Decher, G.; Schlenoff, J. B., eds.; Wiley-VCH: Weinheim, Germany, 2012, p. 83-97.

21. Wu, G.; Zhang, X. In Multilayer Thin Films: Sequential Assembly of Nanocomposite Materials; Decher, G.; Schlenoff, J. B., eds.; Wiley-VCH: Weinheim, Germany, 2012, p. 43-67.

22. Choi, J.; Rubner, M. F.; Macromolecules 2005, 38, 116.

23. Chia, K. K.; Cohen, R. E.; Rubner, M. F.; Chem. Mater. 2008, $20,6756$.

24. Joly, S.; Kane, R.; Radzilowski, L.; Wang, T.; Wu, A.; Cohen, R. E.; Thomas, E. L.; Rubner, M. F.; Langmuir 2000, 16, 1354.

25. Faria, A. C. R.; Menezes, F. D.; Milani, R.; Pereira, M. B.; Gonçalves, R. V.; Horowitz, F.; Giovanela, M.; Machado, G.; Crespo, J. S.; Thin Solid Films 2014, 551, 79.

26. Rasband, W. S.; ImageJ, version 1.46; U. S. National Institutes of Health, Bethesda, Maryland, USA, 2008.
27. Origin, version 9; OriginLab, Northampton, USA, 2007.

28. Motta, V. T.; Bioquímica Básica, 2a ed.; Medbook: Rio de Janeiro, Brasil, 2011.

29. Mayya, K. S.; Schoeler, B.; Caruso, F.; Adv. Funct. Mater. 2003, $13,183$.

30. Grunwaldt, J.; Baiker, A.; J. Phys. Chem. B 1999, 103, 1002.

31. Zhang, L.; Xu, C.; Song, G.; Li, B.; RSC Adv. 2015, 5, 27003.

32. Praveen, P.; Viruthagiri, G.; Mugundan, S.; Shanmugam, N.; Spectrochim. Acta, Part A 2014, 117, 622.

33. Portenkirchner, E.; Neri, G.; Lichtinger, J.; Brumbarov, J.; Rüdiger, C.; Gernhäuser, R.; Kunze-Liebhäuser, J.; Phys. Chem. Chem. Phys. 2017, 19, 8602.

34. Pavia, D. L.; Lampman, G. M.; Kriz, G. S.; Vyvyan, J. R.; Introduction to Spectroscopy, $4^{\text {th }}$ ed.; Cengage Learning: Belmont, USA, 2009.

35. Patra, K. K.; Gopinath, C. S.; ChemCatChem 2016, 8, 3294.

36. Mcgilvray, K. L.; Granger, J.; Correia, M.; Banks, T.; Scaiano, J. C.; Phys. Chem. Chem. Phys. 2011, 13, 11914.

37. Feil, A. F.; Migowski, P.; Scheffer, F. R.; Pierozan, M. D.; Corsetti, R. R.; Rodrigues, M.; Pezzi, R. P.; Machado, G.; Amaral, L.; Teixeira, S. R.; Weibel, D. E.; Dupont, J.; J. Braz. Chem. Soc. 2010, 21, 1359.

38. Chen, X.; Shen, S.; Guo, L.; Mao, S. S.; Chem. Rev. 2010, 110, 6503.

39. Kraeutler, B.; Bard, A. J.; J. Am. Chem. Soc. 1978, 100, 4317.

40. Zhang, L.; Ji, Y.; Wu, D.; Du, S.; Zhang, S.; Zhou, S.; J. Nanosci. Nanotechnol. 2017, 17, 1942.

41. Carrasco-Jaim, O. A.; Ceballos-Sanchez, O.; Torres-Martínez, L. M.; Moctezuma, E.; Gómez-Solís, C.; J. Photochem. Photobiol. A Chem. 2017, 347, 98.

42. Wang, X.; Li, X.; Mater. Sci. Eng. B 2014, 181, 86.

Submitted: March 1, 2019

Published online: July 30, 2019 